\title{
The Increasing Frequency of Cervical Cancer in Korean Women under 35
}

\author{
Chan Hee Han, M.D., Hyun Jung Cho, M.D., Sung Jong Lee, M.D., Jeong Hoon Bae, M.D., Seog \\ Nyen Bae, M.D., Sung Eun Namkoong, M.D. and Jong Sup Park, M.D.
} Division of Gynecologic Oncology, Department of Obstetrics and Gynecology, College of Medicine, The Catholic University
of Korea, Seoul, Korea

Purpose: The goal of this study was to determine the clinical and epidemiological trends of cervical cancer in young Korean women. Social behavior including sexual habits has changed in Korean women, with sexual activity commencing at a younger age. These changes are likely to influence certain risk factors of cervical cancer, resulting in changing trends in the occurrence of the disease.

Materials and Methods: The incidence of cervical cancer in women less than 35 years-old between January 1990 and December 2006 was analyzed, and available medical records from January 1996 to December 2006 were reviewed. The clinical, pathological and epidemiologic characteristics and changing trends among these young patients were analyzed.

Results: Over the last two decades, the incidence of young ( $<35$ years) cervical cancer patients increased,

\section{INTRODUCTION}

Cervical cancer was the most common cancer in women during the 1980s in the Republic of Korea, but its incidence has decreased during the past two decades (1). This change is partly due to the widely accepted cervical cancer screening program, the National Cancer Control Program, started by the Korean government in 1999 (2), and easy accessibility to cancer screening through mandatory health insurance. Although the incidence of the disease has decreased, cervical cancer is still the $5^{\text {th }}$ most common malignancy in Korean women, and more than 3,000 women develop this disease every year in Korea (1).

Recently, a declining birth rate and increased life expectancy have changed the demographic characteristics of the Korean

Correspondence to: Jong Sup Park, Department of Obstetrics and Gynecology, Kangnam St. Mary's Hospital, 505 Banpo-dong, Seocho-gu, Seoul 137-040, Korea. (Tel) 82-2-590-1484, (Fax) 82-2-595-1549, (E-mail) jspark@catholic.ac.kr

Received January 2, 2008, Accepted March 18, 2008

This study was supported by a grant from the National R \& D Program for Cancer Control, Ministry of Health and Welfare, Republic of Korea (0720510) more patients had an aggressive form of the disease, and there was a higher rate of women with more advanced education. Human papillomavirus (HPV) infection was detected in $94.0 \%$ of the women (63/67) tested. HPV 16 $(82.5 \%)$ and HPV $18(12.7 \%)$ were the two most common viral infections detected throughout the study period.

Conclusions: The changing trends and risk factors identified suggest a need for more active education of young women about cervical cancer prevention strategies. In addition, young women are strongly recommended to undergo a regular screening test and HPV vaccination. (Cancer Res Treat. 2008;40:1-5)

Key Words: Uterine cervical neoplasms, Incidence, Epidemiology, Sexual behavior, Human papillomavirus (HPV), Young patients

society. Currently, the Korean society is one of the most rapidly aging cultures in the world. Given this situation, cervical cancer in young women might become a significant social burden as most of the affected women are still raising families.

Cervical cancer has numerous risk factors that are related to the reproductive history and sexual activity of women. Among the risk factors, human papillomavirus (HPV) infection, obtained through sexual intercourse and HPV is considered as a major carcinogen. HPV can be classified according to the specific DNA sequence of the virus and protein homologies, and over $40 \mathrm{HPV}$ genotypes have been identified. The high-risk types (HPV-16, HPV-18, HPV-31, HPV-33, HPV-35, HPV-39, HPV-45, HPV-51, HPV-52, HPV-53, HPV-56, HPV-59, and HPV-82) are associated with an increased risk for developing cervical cancer (3).

Over the past few decades, the sexual behavior of young Korean women has changed, and the age of the onset of sexual activity has been getting younger (4). Changes in the sexual behavior of women are likely to affect the characteristics of young women with cervical cancer. Therefore, the goal of this study was to determine the clinical and epidemiological characteristics and changing trends of cervical cancer in young Korean women. An improved understanding of the characteristics and trends of cervical cancer in young patients will help with the patient management as well as with the development of prevention strategies. 


\section{MATERIALS AND METHODS}

We studied patients younger than 35 years-old. The incidence of young $(<35$ years) cervical cancer patients diagnosed between January 1990 and December 2006 was analyzed. Available data on 109 patients, between January 1996 and December 2006, was reviewed and analyzed. We used a specific timeline where three years was considered one review unit for analyzing the data. The patients were grouped according to the year of diagnosis-group I (1996 1998), group II (1999 2001), group III (2002 2004), and group IV (2005 2006).

All patients were clinically staged before treatment, according to the criteria of the FIGO classification at the time of diagnosis. The clinical and pathological findings as well as the epidemiological characteristics and changes were evaluated. Education, smoking behavior, alcohol consumption, age of sexual activity, marital history, and pregnancy history were analyzed as epidemiological factors. The educational status of the women was classified as elementary, secondary (middle school or high school), and higher education (college education).

An HPV DNA chip, PCR-based DNA microarray system, was used to determine HPV genotypes. DNA was isolated from swab samples using a DNA isolation kit, and DNA was amplified by use of the polymerase chain reaction (PCR) using appropriate primers for HPV and $\beta$-globin. The PCR amplified products were hybridized onto the chip and were visualized with a DNA Chip Scanner (Scanarray Lite; GSI Luminics, Ottawa, Canada).

Statistical analysis was performed using the Fisher's exact

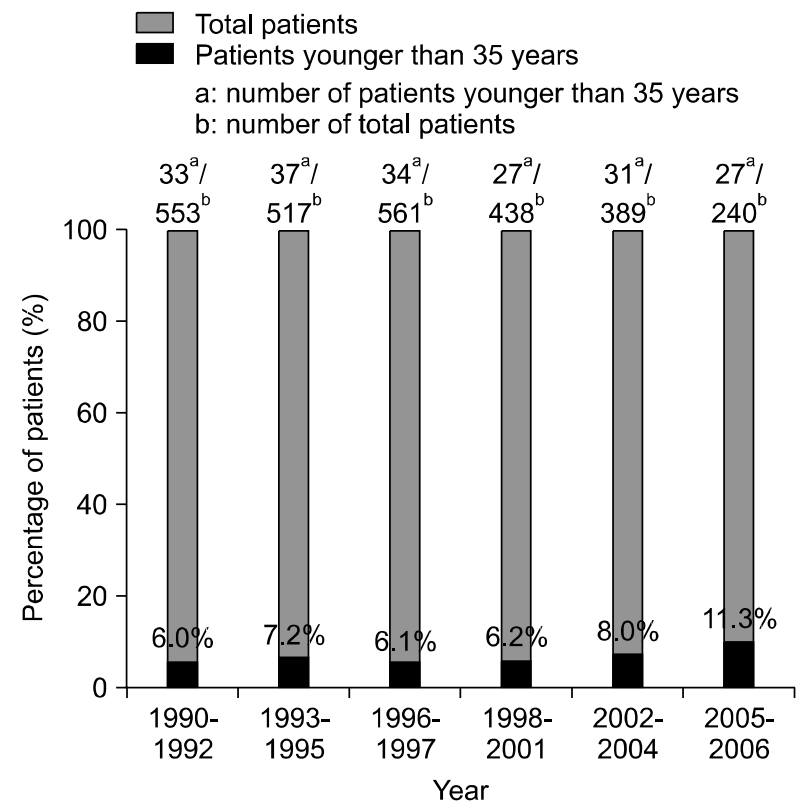

Fig. 1. Increasing proportion of patients younger than 35 years old with cervical cancer $(\mathrm{p}=0.033)$. test, chi-square analysis and linear-by-linear association. Data were considered statistically significant, when the $\mathrm{p}$ value was $<0.05$.

\section{RESULTS}

There were 2,698 cervical cancer patients from January 1990 to December 2006, and 189 patients were younger than 35 years of age. During the study period, the relative incidence of younger patients had increased. The proportion of the younger patients to all patients was as follows: 1990 1992, $6.0 \%$ (33 of 553); 1993 1995, 7.2\% (37 of 517); 1996 1998, $6.1 \%$ (34 of 561); 1999 2001, 6.2\% (27 of 438); 2002 2004, $8.0 \%$ (31 of 389); 2005 2006, $11.3 \%$ (27 of 240) $(\mathrm{p}=0.033$, Fig. 1).

The medical records of 109 patients, between January 1996 and December 2006, were available for evaluation. The mean age of patients, age at marriage and age at first delivery were $30.8 \pm 2.8$ years, $24.1 \pm 3.2$ years and $25.6 \pm 3.3$ years, respectively. Among several epidemiologic factors, education and pregnancy history (gravida) were noted to have significantly changed. Over time, women with more education (college education) increased ( $\mathrm{p}=0.003$, Table 1)- 1996 1998, 26.5\%; 1999 2001, 22.2\%; 2002 2004, 38.7\%; 2005 2006, 55.6\%, and $87.9 \%$ of women received at least a high school education. Thirty-eight $(33.9 \%)$ of the patients were high gravida $(\geq 4)$ and $32(26.9 \%)$ of the patients had never been pregnant. The proportion of women with high gravida $(\geq 4)$ had decreased over time $(\mathrm{p}=0.015$, Table 1$)$.

HPV testing revealed that HPV-16 and HPV-18 genotypes accounted for $84.5 \%$ of the HPV infections. Sixty-seven patients from the year 2000 were tested for the HPV type, and 63 of 67 patients $(94.0 \%)$ were infected. All patients were infected with a high-risk HPV type as a single or combined infection. HPV-16 was the most prevalent viral type identified $(82.5 \%, 52 / 63)$, followed by HPV-18 (12.7\%, 8/63). HPV-58 $(6.3 \%, 4 / 63)$ and HPV-33 $(6.3 \%, 4 / 63)$ were the third most common viral infections. The prevalence of double viral infections was $12.7 \%$ and triple or quadruple infections were

Table 1. Trends in education and number of pregnancies in young $(<35$ years $)$ cervical cancer patients

\begin{tabular}{|c|c|c|c|c|c|}
\hline & $\begin{array}{l}\text { Group } I^{\mathrm{a}} \\
(\mathrm{n}=34)\end{array}$ & $\begin{array}{c}\text { Group } \text { II }^{\mathrm{b}} \\
(\mathrm{n}=27)\end{array}$ & $\begin{array}{c}\text { Group III } \\
(n=31)\end{array}$ & $\begin{array}{c}\text { Group } I^{\mathrm{d}} \\
(\mathrm{n}=27)\end{array}$ & d \\
\hline \multicolumn{5}{|c|}{ Education, No. (\%) } & 0.003 \\
\hline Elementary & $3(8.8)$ & $1(3.7)$ & $2(6.5)$ & $3(11.1)$ & \\
\hline Secondary* & $22(64.7)$ & $20(74.1)$ & $17(54.8)$ & $9(33.3)$ & \\
\hline Higher $^{\dagger}$ & $9(26.5)$ & $5(22.2)$ & $12(38.7)$ & $15(55.6)$ & \\
\hline \multicolumn{5}{|c|}{ Gravida, No. (\%) } & 0.015 \\
\hline$<4$ & $18(52.9)$ & $20(74.1)$ & $19(61.3)$ & $24(88.9)$ & \\
\hline$\geq 4$ & $16(47.1)$ & $7(25.9)$ & $12(38.7)$ & $3(11.1)$ & \\
\hline
\end{tabular}

${ }^{\mathrm{a}}$ Patients from years 1996 to 1998 , ${ }^{\mathrm{b}}$ Patients from years 1999 to 2001, 'Patients from years 2002 to 2004, ${ }^{\mathrm{d}}$ Patients from years 2005 to 2006. *Middle or high school education, ${ }^{\dagger}$ College education. 
Table 2. Distribution of HPV genotypes in HPV-positive cases with cervical neoplasia and the prevalence of single and multiple infections

\begin{tabular}{lcc}
\hline HPV* type & No. & $\begin{array}{c}\text { Percentage of } \\
\text { patients }(\%)\end{array}$ \\
\hline High risk & $52(45+7)^{\dagger}$ & 82.5 \\
HPV-16 & $8(5+3)$ & 12.7 \\
HPB-18 & $4(3+1)$ & 6.3 \\
HPV-33 & $2(1+1)$ & 3.2 \\
HPV-45 & $4(3+1)$ & 6.3 \\
HPV-58 & $1(0+1)$ & 1.6 \\
Low risk & & \\
HPV-6 & 55 & 87.3 \\
Single or double infections & 8 & 12.7 \\
$\quad$ Single infection & \\
$\quad$ Double Infections & \\
\hline
\end{tabular}

*human papillomavirus. ${ }^{\dagger}$ Represented as the total number of cases (No. of single infection + No. of double infections).

not detected (Table 2).

Ten $(8.4 \%)$ of 119 patients were treated primarily with concurrent chemoradiation therapy (CCRT) due to the presence of an advanced stage of the disease. One-hundred- nine (91.6\%) of the 119 patients were surgically treated with or without postoperative adjuvant treatment. Among the surgically treated patients, $84(77.1 \%, 84 / 109)$ patients underwent a radical hysterectomy (type III) with pelvic lymph node dissection (PLND), 16 patients (14.7\%, 16/109) underwent a type I hysterectomy without PLND, and nine patients $(8.3 \%, 9 / 109)$ were treated by cold knife conization.

The proportion of patients who had a tumor larger than 4 $\mathrm{cm}$ in diameter had increased during the time of review; however, there was no statistical significance or shift in the disease stages. Eighty-nine (74.7\%) of the patients had disease confined to the cervix-stage Ia, $33(27.7 \%)$; stage Ib1, 43 $(36.1 \%)$ and stage $\mathrm{Ib} 2,13(10.9 \%)$.

Pelvic lymph nodes were positive for metastases in 16 patients (19.0\%) who received a radical hysterectomy (type III) with pelvic lymph node dissection. The mean number of dissected lymph nodes was $48.4 \pm 14.4$, and there was no statistical difference in the number of dissected lymph nodes between the study groups-group I (1996 1998), 48.8 \pm 14.0 ; group II (1999 2001), 54.0 \pm 19.2 ; group III (2002 2004), $45.2 \pm 11.8$; group IV (2005 2006), $46.7 \pm 15.7$. The rate of positive pelvic lymph node metastasis significantly increased over the study period $(\mathrm{p}=0.038$, Table 3 ). No other pathological findings, except for lymph node metastases, changed during the study period. Among the histological subtypes, a squamous cell carcinoma was the most common cell type (85.3\%), and the other types (adenocarcinoma, adenosquamous carcinoma, or others) were identified in $14.7 \%$ of cases (Table 3 ).

\section{DISCUSSION}

Although the cervical cancer rate has decreased since the
Table 3. Distribution of stage, lymph node metastasis and histology in young patients

\begin{tabular}{|c|c|c|c|c|c|}
\hline & $\begin{array}{l}\text { Group } I^{\mathrm{a}} \\
(\mathrm{n}=34)\end{array}$ & $\begin{array}{c}\text { Group } \text { II }^{b} \\
(n=27)\end{array}$ & $\begin{array}{c}\text { Group } \text { III }^{\mathrm{c}} \\
\quad(n=31)\end{array}$ & $\begin{array}{c}\text { Group IV } \\
(n=27)\end{array}$ & p-value \\
\hline \multicolumn{5}{|c|}{ Stage, No. (\%) } & $\mathrm{NS}^{*}$ \\
\hline Ia & $10(29.4)$ & $12(44.4)$ & $6(19.4)$ & $5(18.5)$ & \\
\hline Ib1 & $13(38.2)$ & $9(33.3)$ & $12(38.7)$ & $9(33.3)$ & \\
\hline $\mathrm{Ib} 2$ & $2(5.9)$ & $1(3.7)$ & $5(16.1)$ & $5(18.5)$ & \\
\hline II & $6(17.6)$ & $3(11.1)$ & $3(9.7)$ & 7 (25.9) & \\
\hline III & $3(8.8)$ & $1(3.7)$ & $3(9.7)$ & $0(0.0)$ & \\
\hline IV & $0(0.0)$ & $1(3.7)$ & $2(6.5)$ & $1(3.7)$ & \\
\hline \multicolumn{5}{|c|}{ LN metastasis, No. (\%) } & 0.038 \\
\hline Negative & $20(90.0)$ & $17(89.5)$ & $16(76.2)$ & $15(68.2)$ & \\
\hline Positive & $2(9.1)$ & $2(10.5)$ & $5(23.8)$ & 7 (31.8) & \\
\hline \multicolumn{5}{|c|}{ Histology, No. (\%) } & $\mathrm{NS}^{*}$ \\
\hline $\mathrm{SCC}$ & $30(88.2)$ & $25(92.6)$ & $23(74.2)$ & $22(81.5)$ & \\
\hline $\begin{array}{c}\text { Adenocar- } \\
\text { cinoma }\end{array}$ & $0(0.0)$ & $2(7.4)$ & $5(16.1)$ & $3(11.1)$ & \\
\hline $\begin{array}{l}\text { Adeno- } \\
\text { squamous } \\
\text { carcinoma }\end{array}$ & $3(8.8)$ & $0(0.0)$ & $0(0.0)$ & $2(7.4)$ & \\
\hline $\begin{array}{l}\text { Others or } \\
\text { combined }\end{array}$ & $1(2.9)$ & $0(0.0)$ & $3(9.7)$ & $0(0.0)$ & \\
\hline
\end{tabular}

${ }^{\mathrm{a}}$ Patients from years 1996 to 1998 , ${ }^{\mathrm{b}}$ Patients from years 1999 to 2001, 'Patients from years 2002 to 2004 , ${ }^{\mathrm{d}}$ Patients from years 2005 to 2006, *not-specific; SCC, squamous cell carcinoma.

implementation of widespread screening in developed countries (5-7), cervical cancer is the second most common cancer among women, and an estimated 493,000 new patients and 274,000 deaths occur per year worldwide (8). The incidence of cervical cancer varies with the socioeconomic status of a country. In developing countries, cervical cancer accounts for $15 \%$ of female cancers, but in developed countries, it is responsible only for $3.6 \%$ of female cancers (8). In Korea, the number of affected patients had decreased until 2000, but cervical cancer is still a major health problem for Korean women (1).

The major cause of cervical cancer is HPV infection acquired during sexual activity. The highest incidence of HPV infection has been found in sexually active women younger than 25 years of age (9). The prevalence of HPV infection in Korean women is about $15 \%$ with particular geographic variations; Incheon and Busan are the two most prevalent areas (10). HPV-16 and HPV-18 are the most common viruses that infect women, regardless of the histology $(11,12)$. HPV-16 and HPV-18 have genotypes associated with a high-risk for the development of cervical cancer and its precursor lesions. The viruses are responsible for about $70 \%$ of cervical cancers and about $50 \%$ of cervical intraepithelial neoplasia (CIN) grade 3 (CIN3) lesions (13). Shin et al. reported on the HPV prevalence among young women in the Busan area (14). In that study, young women had a higher rate of HPV infection, most frequently with HPV-16 and HPV-18, than in older patients. The risk for HPV increased with an increase in sexually activity. Overall, HPV infection in cancer patients has been reported to be about 
$95 \%$ to $96 \%$ in Korea. In our study group, patients younger than 35 years had a $94.0 \%$ rate of HPV infection, similar to the overall HPV infection rate of $95.8 \%$ (12). The prevalence of the specific type of HPV infection was similar to that reported in a previous study (12) where HPV-16 and HPV-18 were found as the major pathogens (84.5\%) and HPV-58 and HPV-33 were the third most common pathogens $(11.2 \%)$. The overall infection rate and the specific type and prevalence of HPV were not different over time.

Other risk factors for cervical cancer are a young age at the time of first intercourse, multiple sexual partners, a history of sexually transmitted disease, cigarette smoking and high parity (15). These risk factors are related to the reproductive history and the sexual behavior of women. The rapid cultural changes in Korean society have affected sexual behavior as well as social activity. In a worldwide study, Weillings et al. reported that more men and women have premarital sex, and they have two or more sexual partners because of later marriage (16). Kim et al. recently reported that the age of sexual activity is getting younger in Korean society (4). These changes in the sexual activity of Korean women lead to more opportunity for HPV infection. This is likely one of the possible reasons for the increasing incidence of young patients with cervical cancer during the last two decades. Another possible reason of an increased incidence of young patients in our study is a decrease in the incidence of patients at ages 50 59 years. Chung et al. have reported on cervical cancer incidence and survival in Korea from 1993 to 2002 (17). These investigators reported a significantly decreasing incidence in women aged 50 59 years. The decreased incidence in old-aged patients might cause a relatively increasing incidence in young patients. Among the epidemiological factors reviewed among the young patients, education and pregnancy history were significant. The education of women significantly increased during the study period. This finding is not consistent with previous studies on the risk factors associated with cervical cancer. Another inconsistent finding for the risk factors was a decreasing proportion of women with high gravida $(\geq 4)$. The correlation between cervical cancer and these two factors could not be explained in this study. However, increased education and a smaller number of pregnancies are likely related to the changing social trends in Korea. A further study is needed to understand these social trends and their relationship to the development of disease risk.

This study has several limitations. It was difficult to obtain all of the required patient information as certain behaviors are unacceptable in Korean society, such as women smoking, drinking and sexual activity before marriage. Most women would not discuss their sexual behavior.

Cervical cancer has several risk factors for recurrence and prognosis (18). Intermediate risk factors are deep stromal invasion, lympho-vascular space invasion, and the size of the tumor, and high risk factors are a positive resection margin, lymph node metastasis and parametrial invasion. Several studies have reported the effect of age on the prognosis and characteristics in young patients. Kastritis et al. and Russell et al. reported that age alone was not a significant prognostic factor $(19,20)$, while other investigators have reported an increased prevalence of aggressive disease and a poorer prognosis in younger patients. Mariani et al. reported that younger patients had larger tumors as compared to older patients, with a shift of the younger patients to stage IB disease, although no statistical significance was noted (21). Murrell et al. and Elliott et al. reported a higher frequency of lymph node metastasis and disease that was more aggressive in young patients $(22,23)$. Our study also demonstrated that younger patients were presenting with disease that is more aggressive during the study period; there was a higher frequency of lymph node metastasis and larger tumors, although the tumor size differences were not statistically significant. These findings correspond to findings from other studies and our patients may have a poorer prognosis, as has been similarly noted in previous reports (21-23).

The most common histology of cervical cancer is squamous cell carcinoma in both young and old patients. The incidence of adenocarcinoma and adenosquamous carcinomas has been reported to have increased in young patients; however, the results of our study did not demonstrate this increase (24).

\section{CONCLUSION}

The results of our study showed that cervical cancer is occurring more frequently in young patients, and that these patients have a more aggressive form of the disease than noted in the past; with an increase in lymph node metastases and tumor size. We also found that these women are more highly educated and have fewer pregnancies.

Although our study group does not represent all women in Korea and a further large-scale study is needed and the changing trends should be considered for better patient care.

The use of cervical cytology is effective in cancer screening. However, it still has high false-negative rate (25). For the prevention of HPV infection, a vaccination program has recently commenced, but it has not yet been established as essential vaccination program. As prevention programs, welleducated young women should be informed about the risks and benefits of screening and the benefit of vaccination so that prevention strategies can be used in a timely manner. Such efforts are likely to decrease the rate of HPV infection and increase the rate of early detection of cervical cancer so that treatment can be implemented promptly with the hope of greater efficacy, resulting in a decrease of cancer occurrence in young women. In a further study, efficacy and needs of closer follow-up and more aggressive treatment to young patients should be studied, because of adverse features in young patients observed in several studies, including the present study.

\section{REFERENCES}

1. Lee MY, Cho CH, Kwon SH, Song DK, Chung SW, Kang $\mathrm{HO}$, et al. Annual report of gynecologic cancer registry program in Korea for 2002 (Jan. 1st, 2002 - Dec. 31st, 2002). Korean J Obstet Gynecol. 2004;47:1029-70.

2. Kwak MS, Park EC, Bang JY, Sung NY, Lee JY, Choi KS. Factors associated with cancer screening participation, Korea. J Prev Med Pub Health. 2005;38:473-81.

3. Schiffman M, Herrero R, Desalle R, Hildesheim A, Wacholder $\mathrm{S}$, Rodriguez $\mathrm{AC}$, et al. The carcinogenicity of human papil- 
lomavirus types reflects viral evolution. Virology. 2005;337: 76-84.

4. Kim CJ, Kim BG, Kim SC, Kim YT, Kim YM, Park SY, et al. Sexual behavior of Korean young women: Preliminary study for the introducing of HPV prophylactic vaccine. Korean J Gynecol Oncol. 2007;18:209-18.

5. Quinn MA, Benedet JL, Odicino F, Maisonneuve P, Beller U, Creasman WT, et al. Carcinoma of the cervix uteri. Int $\mathbf{J}$ Gynaecol Obstet. 2006;95(Suppl 1):S43-103.

6. Pecorelli S, Favalli G, Zigliani L, Odicino F. Cancer in women. Int J Gynaecol Obstet. 2003;82:369-79.

7. Parkin DM. Cancer in developing countries. Cancer Surv. 1994;19-20:519-61.

8. Parkin DM, Bray F, Ferlay J, Pisani P. Global cancer statistics, 2002. CA Cancer J Clin. 2005;55:74-108.

9. Koutsky L. Epidemiology of genital human papillomavirus infection. Am J Med. 1997;102:3-8.

10. Jung WW, Chun T, Sul D, Hwang KW, Kang HS, Lee DJ, et al. Strategies against human papillomavirus infection and cervical cancer. J Microbiol. 2004;41:255-66.

11. Park TC, Kim CJ, Koh YM, Lee KH, Yoon JH, Kim JH, et al. Human papillomavirus genotyping by the DNA chip in the cervical neoplasia. DNA Cell Biol. 2004;23:119-25.

12. Bae JH, Lee SJ, Kim CJ, Hur SY, Park YG, Lee WC, et al. Human papillomavirus (HPV) type distribution in Korean women: a meta-analysis. J Microbiol Biotechnol. 2008; April [in press].

13. Becker TM, Wheeler CM, McGough NS, Parmenter CA, Jordan SW, Stidley CA, et al. Sexually transmitted diseases and other risk factors for cervical dysplasia among southwestern Hispanic and non-Hispanic white women. JAMA. 1994;271: $1181-8$.

14. Shin HR, Lee DH, Herrero R, Smith JS, Vaccarella S, Hong $\mathrm{SH}$, et al. Prevalence of human papillomavirus infection in women in Busan, South Korea. Int J Cancer. 2003;103: 413-21.

15. International Collaboration of Epidemiological Studies of Cervical Cancer. Comparison of risk factors for invasive squamous cell carcinoma and adenocarcinoma of the cervix: collaborative reanalysis of individual data on 8,097 women with squamous cell carcinoma and 1,374 women with adenocarcinoma from 12 epidemiological studies. Int J Cancer. 2006;120:885-91.

16. Wellings K, Collumbien M, Slaymaker E, Singh S, Hodges Z, Patel D, et al. Sexual behavior in contest: a global perspective. Lancet. 2006;368:1706-28.

17. Chung HH, Jang MJ, Jung KW, Won YJ, Shin HR, Kim JW, et al. Cervical cancer incidence and survival in Korea : 1993-2002. Int J Gynecol Cancer. 2006;16:1833-8.

18. Atahan IL, Onal C, Ozyar E, Yiliz F, Selek U, Kose F. Long-term outcome and prognostic factors in patients with cervical carcinoma: a retrospective study. Int J Gynecol Cancer. 2007;17:833-42.

19. Kastritis E, Bamia A, Bozas G, Koutsoukou V, Voulgaris Z, Vlahos G, et al. The impact of age in the outcome of patients with advanced or recurrent cervical cancer after platinumbased chemotherapy. Gynecol Oncol. 2000;104:372-6.

20. Russell JM, Blair V, Hunter RD. Cervical carcinoma: prognosis in younger patients. Br Med J. 1987;295:300-3.

21. Mariani L, Iacovelli A, Vincenzoni C, Diotallevi FF, Atlante M, Lambardi A. Cervical carcinoma in young patients: clinical and pathological variables. Int J Gynaecol Obstet. 1993;41: 61-6.

22. Murrell DS, Helm CW, Bourne H. Carcinoma of the cervix in women up to 35 year of age. Clinical Oncol. 1990;2:260-3.

23. Elliott PM, Tattersall MH, Coppleson M, Russel P, Wong F, Coates AS, et al. Changing character of cervical cancer in young women. BMJ. 1989;298:288-90.

24. Vinh-Hung V, Bourgain C, Vlastos G, Cserni G, De Ridder M, Storme G, et al. Prognostic value of histopathology and trends in cervical cancer: a SEER population study. BMC Cancer. 2007;7:164.

25. Kirschner B, Simonsen K, Junge J. Comparison of convertntional Papanicolaou smear and SurePath liquid-based cytology in the Copenhagen population screening programme for cervical cancer. Cytopathology. 2006;17:187-94. 